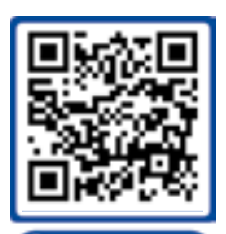

\title{
REHABILITATION NEED FOR MIGRANT POPULATIONS: PHYSIOTHERAPY TREATMENT OF THE POST-TRAUMATIC STRESS DISORDER (PTSD) AND CHRONIC PAIN FROM TORTURE RESULTS
}

MSc student GarofanoMarina ${ }^{1}$, MSc student Ascoli Matteo Maria ${ }^{2}$, MSc Palumbo Roberta $^{1}$

\author{
${ }^{1}$ Fisioterapista SIFiR \\ ${ }^{2}$ Fisioterapista AUSL di Modena e SIFiR
}

KEYWORDS: migrant, refugees, rehabilitation, physiotherapy, chronic pain, foot, sensibility, torture, PTSD

\section{ABSTRACT}

The migration phenomenon in recent years is assuming considerable proportions, so it is necessary to consider the need for health of migrant populations. The present work investigate, in particular, the rehabilitation need of the migrant populations. From the analysis of the literature about the incidence and prevalence of the deseases, two conditions of physiotherapic interest come to light: Post Traumatic Stress Disorder (PTSD) and the rehabilitation from torture outcomes. The analysis of the literature was carried out on the most important databases: PubMed, Scopus and PEDro.

In PTSD relaxation techniques like BBAT appear to be essential In chronic pain from torture, manual therapy, progressive exercises, balance training are recommended. Unfortunately, the rehabilitative intervention in no study is well clarified in terms of duration, frequency and type of exercise, so repeatability is definitely invalidated and the effectiveness of it continues to be uncertain.

\section{NUMBERS OF THE MIGRATION PHENOMENON}

During 2016 numbers of migration phenomenon towards Italy has been terribly high: in fact we had the highest number of disembarked people $(181.436,+18 \%$ compared to the previous year), but also people hosted in specific structures $(176.554,+70 \%$ compared to 2015 and $+698 \%$ compared to 2013 ); foreign minors who arrived in Italy alone were 25.772 units, like those who came two years before. (D'amato, Bonfigli, Cenci, \& Maraglino, 2017). Another extremely dramatic number is 5.143 people who died in the sea and this data has to be added at over 10.000 estimated since 2011. (Geraci $\&$ Hamad, 2011). The reduction of the births by foreign citizens is also an important part of the overall reduction of births rate in our country. Just consider that during 2016 on amount of 474.000 births, $19,4 \%$ has a foreign mother (is the same percentage reported in 2015): these 92.000 babies are $2,2 \%$ less than the year before and 69.000 of them ( $14,7 \%$ of the total amount of the babies) have father and mother both foreigners (D'amato et al., 2017). All the data above reported surely give us the idea of great complexity and variability and it's not difficult to understand the social and economic ripercussions related. In order to develop programming tools and governance strategies, in 2017 were established some guidelines. First of them surely was the protection of foreign minors, of intentional violence and torture victims and medical hospitality of refugees (Ministero della Salute, 2017).

\section{IDENTIFICATION OF THE}

REHABILITATION NEED

The present work arises following the desire to investigate the rehabilitation need of the migrant populations.
From the analysis of the literature about the incidence and prevalence of the deseases, two conditions of physiotherapic interest come to light: Post traumatic stress disorder (PTSD) and the rehabilitation from torture outcomes. Among them, there's a focus on the falanga torture, a method in which the soles of the feet (especially the heels) have to be brutally and repeatedly hit using sticks, iron bars, causing chronic pain and foot sensibility deficit.

\section{POST-TRAUMATIC STRESS \\ DISORDER (PTSD)}

In the ICD 10 the PTSD is defined as an anxiety disorder accompained by a triad of symptoms, like intrusions, avoidance, hyperarousal (Frommberger, Angenendt, \& Berger, 2014)the one-month prevalence of post-traumatic stress disorder (PTSD. The attempt to think back again the trauma fails and lead to a dysfunctional avoidance behaviour, so symptoms become prolonged and chronics. PTSD also includes dissociative symptoms (e.g. total or partial amnesia) and emotional numbness (Frommberger et al., 2014)the one-month prevalence of post-traumatic stress disorder (PTSD. Sometimes the affected person seeks "relief" (often worsening the situation) with alcohol abuses and various drugs. The above mentioned disturb also involves the onset of physical symptoms such as muscle tensions, breathing difficulties, changes in psychomotor behaviour, cardio-respiratory and gastro-intestinal symptoms (Pacella, Hruska, \& Delahanty, 2013)as well as moderators of this relationship. Literature searches yielded 62 studies examining the impact of PTSD/PTSS on physical health-related quality of life (HR-QOL, physical disabilities and chronic pain following injuries resulting from torture (Buhmann, 2014).

The evaluation of the organic symptoms from post-trau- 
matic stress disorder is being investigated by a Danish study, in wich healty control are compared with a group of immigrates and one of Danish war veterans. The aim of this study is evaluate the effectiveness of the Body Awareness Movement Quality and Experience Scale (BAS MQ-E) in assessing stability, balance, flexibility and coordination in movement. The results achieved by the patiens of the study group were poorer than the medical supervisions and also showed more muscular tensions, pain, breathing limitations and in the Activity of Daily Living (ADL) (Nyboe, Bentholm, \& Gyllensten, 2017).

Mental healthy and psychosocial tension problems of the refugees in Western countries belong to the traumatic and stressfull expieriences made during wars and after their arrival, such as waiting moments during asylum procedures, poverty, lackness of social support and discriminations (Danon \& Miltenburg, 2001). In order to work on this kind of problems, in 2018 was published a Danish study (Beck et al., 2018), in which has been shown that for each participant was made a global rehabilitation proposal: it has a multidisciplinary approach including physiotherapy and psycomotor treatments. Adding musicotherapy (Longacre, Silver-Highfield, Lama, \& Grodin, 2012)including chronic pain, major depressive disorder, posttraumatic stress disorder (PTSD to all the above mentioned treatments, came out that it can improve the adherence and reduce the pain which often accompain pathology with rehabilitation interest (MartinSaavedra, Vergara-Mendez, \& Talero-Gutiérrez, 2018) as reported in systematic reviews and meta-analysis. Methods: A search of articles published between 2004 and 2017 was conducted on Pubmed, ScienceDirect, Scopus, SCIELO, SpringerLink, Global Health Library, Cochrane, EMBASE and LILACS. Search, quality assessment, and data extraction was done independently by two researchers. Results: Most of reviews found a significant effect of music on pain. All analyses had a high heterogeneity, and only acute pain and music delivered under general anesthesia had moderate heterogeneity. No differences were found when music was chosen by the patient. Music type and its characteristics are scantly described and in terms that lack validity. Conclusions: More focused trials and reviews, objective language for music, and trials with music chosen by its characteristics are required.",'author":

[\{“dropping-particle":",,,'family":,'MartinSaavedra","given":"Juan Sebastian","non-dropping-particle":",","parse-names":false,"suffix": "', $\},\{$ “dropping-particle":",,'family":"VergaraMendez",,given":,'Laura Daniela","non-dropping-particle":",,",parse-names":false,"suffix":" "\},\{“dropping-particle":",,’family":’Talero-Gu tiérrez","given":"'Claudia","non-droppingparticle",",,"parse-names":false,"suffix":",'\}],"con tainer-title":"'Complementary Therapies in Clinical Practice","id":.'ITEM-1","'issue":."March","issued": \{“d ate-parts":[[“2018”]]\},"page":"'103-114","title":.'Music is an effective intervention for the management of pain: An umbrella review","type":"article-journal"," volume":"32"'\},"uris":["http://www.mendeley.com/ documents/?uuid=5ea9296a-c077-4980-94f2-283e2b7 2e3da"]\}],"mendeley": ‘“formattedCitation":"(MartinSaavedra, Vergara-Mendez, \& Talero-Gutiérrez, 2018. Similar results are achieved with treatments based on the narration of tortures of the survivors coming from unsafe region of Middle East and North Africa (Kirstine Viller Hansen, Sloth Hansen-Nord, Smeir, Engelkes-Heby, \&
Modvig, 2018). Narration is associated to a reduction of PTSD symptoms, anxiety, depression, pain perception, disability level and improvements in self-reported health. Consequently it seems necessary reduct linguistic barriers between therapist and patient. In Scandinavian countries physiotherapy is an integral part of the multidisciplinar rehabilitation treatments for the traumatized refugees and its aim is to alleviate and cope with pain, correct dysfunctions and regain body awareness (Madsen, Carlsson, Nordbrandt, \& Jensen, 2016).

A review of the Danish Literature on the evidence-based treatments for traumatized refugees concluded that them were limited, but Basic Body Awareness Therapy (BBAT) had shown promittent results in other patiens with chronic pain and psychiatric desease. BBAT was invented in the early 1970 by Gertrud Roxendal (Roxendal, 1985)body experience, body image, body image boundaries, body management, body awareness, movement pattern and general bodily dysfunctions. The treatment method, Body Awareness Therapy, is described in two techniques, based on two complementary aspects of body consciousness and motor behaviour: 1. a Swedish physiotherapist. This treatment involves an holistic approach and it's rooted in the Eastern tradition of movement. The exercises make up by the BBAT are based on easy and slow movements aimed at improving the awareness of the biomechanical, physiological, psycosocio-cultural and existential aspects of the movement, but also on the cognition of the body as the basis of the self-awareness (Blaauwendraat, Levy Berg, \& Gyllensten, 2017).

BBAT is the study object in a Danish trial in which 26 patients carefully evaluated were directed to a psychotherapic, pharmacological and physiotherapic treatment, based on BBAT and awareness of the own body to fight against pain and stress. The proposal included 16-18 weeks of treatment in which physiotherapic and psycotherapic aspects took place in different times. Unfortunately, the absence of control groups doesn't allow to diversify risults from all the treatments, even though had produced an improvement in the medical case (Palic \& Elklit, 2009).

This kind of approach was very appreciated also by the three patients who underwent in semi structured interviews at the end of the BBAT treatment period. These people have also noticed that the presence of the physiotherapist increases compliance and the therapy quality, compared to the self-guided exercise (Madsen et al., 2016). At the same time also Arabic speaking patients who joined this study in 2015, have shown their improvements regarding psychiatric and somatic symptoms, the quality of life and about the level of functioning and quality of movement during treatment with BBAT (Stade, Skammeritz, Hjortkjær, \& Carlsson, 2015).

Similar results are present in a study that include Tai Chi, an ancient Chinese technique which uses slow movements to produce psycho-physical relax and increases body awareness (Grodin, Piwowarczyk, Fulker, Bazazi, \& Saper, 2008). Tai Chi is also used in other desease rehabilitation as Parkinson, with good results (Yang, Li, Gong, Zhu, \& Hao, 2014).

\section{TORTURES AND VIOLENCES}

In the International Legal System the word "torture" means a voluntary infliction of physical or psychological pain, sometimes exerted by state authorities themselves for many reasons (Rica, 2016).

The "Convention against tortures and other cruelties, 
treatments or degrading, inhuman punishments" was ratified by 174 states of the 192 members of United Nations (Rights \& Cruel, 2012). However don't exist global estimates and several studies which report the prevalence of the torture in specific countries or territories that are or have been in war, where it's known that torture is a widely used tool of coercion.

As regard the prevalence of torture among asylum-seeking refugees, above is reported the situation in some $\mathrm{Eu}-$ ropean countries.

- England: about half of asylum-seeking refugees who go to health facilities for chronic pain was a torture victim (A. C. D. C. Williams, Peña, \& Rice, 2010).

- Denmark: about half of the first generation of asylum-seeking refugees was tortured (Masmas et al. 2008).

- Italy: according to the data collected by the Medical Volunteers Against Torture Association, about the $80 \%$ of the asylum-seeking refugees who have passed through Libia have been tortured (Camilli, 20017).

Torture methods can be both psychological and physical, although there isn't a clear distinction because all hit body and soul, as Basoglu et al demonstrated (Başoğlu, Livanou, \& Crnobarić, 2007).

Some psychological torture methods are false executions, like to be forced to see tortured family and friends, sexual abuses, sleep deprivation and isolation (Olsen, Montgomery, Carlsson, \& Foldspang, 2006). The most often reported physical methods are: unsystematic beatings, violences carried out on the whole body (often described as generalized tortures) with various tools, being tied for long periods in painful positions, stress and coercion techniques (Olsen, Montgomery, Bøjholm, \& Foldspang, 2006)back, and feet. Methods: 221 refugees, 193 males and 28 females, previously exposed to torture in their home country, were subject to a clinical interview at a rehabilitation clinic for torture victims. The interview focused on exposure to torture and somatic symptoms prevalent at examination. Results: The mean number of times imprisoned was 2.3; the mean number of months imprisoned was 19.7; the mean duration from initial imprisonment to final release was 3.7 years; and the mean duration from final release to preliminary interview was 8.4 years. The most frequent physical torture method reported was beating $(92.3 \%$.

Because of the significant rehabilitative consequences, now let's focus the attention on the falanga torture. This definition is used to describe systematic and repeated beatings that causes traumas to the sole of the feet and widely practiced expecially in Middle East countries. Linked torture victim it's violently struck with wooden or iron bars (Rejali, 2009). After that, some victim put their feet in cold water, others are forced to walk during or after they were beated to increase the amount of damage (Rasmussen, Amris, \& Blaauw, 2002).

The entity of the damage depends on various elements such as the chosen tools, the force applied (eg. whipping or hitting) and its duration (Byard \& Singh, 2012). The consequent effects are very difficult to detect clinically, although the permanent damage inflicted on soft tissue of the heels leads to a chronic pain and a difficulty in walking (Savnik et al., 2000)by MRI, possible morphologic characteristics of the heel and ball of the foot, related to falanga and pain in correlation to clinical findings. Magnetic resonance imaging of the foot was obtained in 12 victims exposed to falanga torture and 9 healthy volunteers. Sagittal T1-weighted spin-echo images (TR 616-
840 ms, TE 20 ms (Byard \& Singh, 2012)

Because of the pain, generally the tortured person will be able to walk only for a while (Danneskiold-Samsøe, S., Amris, S., \& Torp-Pedersen, 2007). Among the acute consequences we find internal blooding and swelling of tissues, which disappear spontaneously in 1-2 weeks.

The most serious complicance of the torture is that the cushioning effect of the heel is lost forever. Clinical examinations based on the palpation (Prip \& Persson, 2008)"ISSN":"07498047","'abstract":"OBJECTIVES: To explore clinical findings in men with chronic pain after falanga torture as compared with controls, and to try to understand the nature of the pain mechanisms responsible. METHODS: Eleven male torture victims from the Middle East with chronic pain after falanga, and 11 age, sex, and ethnically matched controls with no history of torture were recruited. All participants were interviewed regarding pain characteristics in the feet and lower legs at rest and when walking. Structural changes and motor and sensory function were clinically assessed according to a standardized protocol. The walking pattern was observed for compensatory gait patterns. RESULTS: The torture victims had pain in their feet and lower legs and a compensated gait pattern, usually with severe pain during walking. Reduced light touch and thermal sensation, tactile dysesthesia, allodynia, and tenderness on palpation were common findings. Structural changes in the feet were found in more than half of the victims, but did not correlate with pain reports. These clinical findings were nonexistent or seen only rarely in controls. DISCUSSION: We found clear clinical signs of nerve injury in the feet. The sensory findings indicated 2 neuropathic pain mechanisms, one dominated by a peripheral pain generator and other by irritative phenomena (dysesthesia, allodynia have reported a reduced elasticity of the heel tissue, thinning of the skin, thickened and irregular plantar aponeurosis.

Chronical pain's aetiology, pathogenesis and disability found after the falanga torture aren't clear yet (Amris, Rasmussen, \& Baykal, 2009). Also the torture confirmation is difficult, especially in cases evaluated after several months after the trauma.

From an epidemiological point of view, in a study conducted at the Kris and Trauma Centrum (KTC) in Stocholm has been examinated 131 torture victims and falanga was reported in $45 \%$ of the cases. It is most commonly found among Bangladeshi, Syrian, Middle East and North Africa patients. $82 \%$ of falanga torture's victims show scars, foot and legs pigmentations, palpable irregularities of the soften tissues, while persistent pain was reported by $48 \%$ of the patients. Signs and symptoms are highly significative when compared with a control group which hadn't suffered from falanga torture ( $\mathrm{p}$ $<0,0001$ ) (Edston, 2009).

Almost all the victims suffer of chronic, widespread and high intensity pain (Kaur, 2017). However, regional painful conditions such as headache, backpain, lower limbs, shoulders and upper limbs have recently have been reported.

Thomsen et al. (Thomsen, Eriksen, \& Smidt-Nielsen, 2000)characterising pain types as nociceptive, visceral or neuropathic. Torture victims from the Middle East, treated at the Rehabilitation and Research Centre for Torture Victims (RCT have found a high prevalence of neuropatic pain in falanga torture patiens $(81 \%)$ and partial brachial plexus lesions in $64 \%$ of patients who underwent torture by suspension. 


\section{REHABILITATIVE TREATMENT OF CHRONIC PAIN}

Regarding the rehabilitative treatment of chronic pain in migrant populations there are few evidences in literature. In a 2009 review (Amris \& Rasmussen, 2009) and in a 2015 report (Amris \& Williams, 2015), a quick reference is made to the physiotherapic intervention related to falanga torture, recommending an intervention aimed at limiting overloading damages caused by an altered gait pattern and then the use of of suitable footwear. Various physiotherapy treatments have been recommended, including manual and progressive exercises, balance training based on an individual and systematic assessment aimed at reducing pain, improving function and developing skills of active imitations (Amris \& Williams, 2015). Taping, stabilizing bendage, shoe modifications and orthoses are recommended for improving gait and walking tolerance. No recommendations on pharmacological treatment of the pain have emerged, but Transcutaneus Electrical Nervous Stimulation (TENS) and education on pain self-management based on a cognitive behavioral approach have been suggested as an integral part of the pain management (Amris \& Williams, 2015).

However in the report is underlined the lack of data regarding chronic pain management in the tortured refugees. According to the authors, this lack is linked to the fact that post torture rehabilitation interventions are largely carried out by health professionals who work in human right organizations and today these services remain far from traditional health institution and focuse the attention on psychological problems rather than the clinical ones (Amris \& Williams, 2015).

From 2008 until 2012 Prip et al. have conducted four studies in Denmark (Prip \& Persson, 2008)'"ISSN":."07 498047",'”abstract":'OBJECTIVES: To explore clinical findings in men with chronic pain after falanga torture as compared with controls, and to try to understand the nature of the pain mechanisms responsible. METHODS: Eleven male torture victims from the Middle East with chronic pain after falanga, and 11 age, sex, and ethnically matched controls with no history of torture were recruited. All participants were interviewed regarding pain characteristics in the feet and lower legs at rest and when walking. Structural changes and motor and sensory function were clinically assessed according to a standardized protocol. The walking pattern was observed for compensatory gait patterns. RESULTS: The torture victims had pain in their feet and lower legs and a compensated gait pattern, usually with severe pain during walking. Reduced light touch and thermal sensation, tactile dysesthesia, allodynia, and tenderness on palpation were common findings. Structural changes in the feet were found in more than half of the victims, but did not correlate with pain reports. These clinical findings were nonexistent or seen only rarely in controls. DISCUSSION: We found clear clinical signs of nerve injury in the feet. The sensory findings indicated 2 neuropathic pain mechanisms, one dominated by a peripheral pain generator and other by irritative phenomena (dysesthesia, allodynia (Prip, Persson, \& Sjölund, 2011)particularly the impact of neuropathic pain resulting from falanga (beatings under the feet (Prip, Persson, \& Sjölund, 2012a) (Prip, Persson, \& Sjölund, 2012b).

All the included patients suffered from long-term outcomes related to the various kind of torture they had underwent in the previous years (from 5 to 30 years before) in their homelands. In order to eliminate communication difficulties, interpreters have been used for the 171 pa- tients recruited for the 4 studies. Before starting, all of the patients were evaluated by a multidisciplinar team made up by doctor, psychologist, physiotherapist and social assistant. The inclusion criteria were: 1) a torture victim with asylum in Denmark; 2) physical, psychological and social needs; 3) no obvious psychosis; 4) no abuse of drugs and alcohol; 5) willingness to undertake the treatment.

From these studies emerged that torture victimes suffer from foot and lower legs pain, showing various compensations and pains during their walk. Strong pain is often combined with a reduced tactile and thermal sensitivity. Tactile dysesthesia, allodynia and hypersensitivity to palpation of the plantar fascia or under the heel were found extensively. These clinical results were non-existent or only rarely found in healthy controls. The presence of sensibility alterations has been attributed by the authors to changes that occur at central level, in response to the structure of the chronic pain.

As reported in a 2009 review concerning pain symptoms, the sites where patients most frequently report pain are low back, neck and a widespread pain, so physiotherapy goals are to increase the awareness of their body in order to augment physical activity levels and the functional ability in everyday activities, to promote pain management, increasing self-efficacy level (Sjölund, Kastrup, Montgomery, \& Persson, 2009).

In a 2007 study asylum seekers were studied for 10 years in order to evaluate the association between pain location and type of torture suffered. At baseline, low back pain was associated to a psychologic torture and to a sensory deprivation, while at follow-up there was no significant association between psychological status and physical torture. Foot pain, instead, at baseline was associated to generalized tortures and electric shock, while at the follow-up there was significant association with specific torture locus, age of the first incarceration and duration of imprisonment. Foot pain wasn't linked to psychological violences (Olsen, Montgomery, Bøjholm, \& Foldspang, 2007)back and feet, among previously tortured refugees settled in Denmark, and to compare associations between methods of torture and prevalent pain at baseline and at 10-year follow-up. Methods. 139 refugees previously exposed to torture in their home country were interviewed at a Danish rehabilitation clinic on average 8 years after their final release from confinement and reinterviewed 10 years later. Interviews focused on history of exposure to physical and mental torture and on pain in the head, back and feet prevalent at study. Results. The mean number of times imprisoned was 2.5 and the mean cumulative duration of imprisonment 19.4 months. The most frequent physical torture method reported was beating $(95.0 \%$.

Regarding chronic pain treatment due to torture, from a review published in 2016 emerge the following conclusion: treatment indications are only relative to three type of treatments, two of them consist in a cognitive-behavioral therapy with biofeedback, but without any relevant benefits for pain and disability after the treatment and very weak effects on pain at follow-up. Third study focused on physiotherapy but despite the improvements in terms of disability, didn't seem to have efficacy in the pain treatment (maybe the study was small and understaffed) (de C Williams \& Baird, 2016).

Non-randomized studies included various methods for the treatment of the pain (its management education with or without any physical exercise instructions), that lead to modest or none at all improvements. However, in gen- 
eral, physiotherapy seems to be more accepted and tolerated than psychologic interventions.

In a second revision published in 2017 by Williams et al. emerge the following evidences: pain management starts from providing informations on chronic pain to the patients and must include a therapeutic exercise and a gradual recover of the ADL; very important is a cognitive approach at the treatment of the pain which encourage changes in the behaviour of the people with pain as for maximize autonomy and confidence in pain management (A. C. d. C. Williams \& Amris, 2017).

An interesting explorative study was driven by the Copenhagen Rehabilitation and Research Centre for Torture Victims. In that, 15 Arabian speaking refugees who have chronic pain were asked about what they expect from a rehabilitation program. Patients show their interest toward the physiotherary intervention and express the need for active and passive treatments, which must be combined to educational/preventive joint hygiene interventions, moreover refer the need to fine compensation strategies that are best suited to tackle chronic pain (Persson \& Gard, 2013).

\section{CONCLUSIONI}

In conclusion, from what has been found in literature, it's clear that falanga tortured patiens show chronic pain and foot sensiblity alterations more than the others. The treatment of these kind of disorders includes a well structured rehabilitation proposal with a neurocognitive approach (eg. Cognitive therapeutical exercise, Mirror Therapy, Motor Imagery, Action Observation Therapy) (Ciriello \& Calabrese, 2019) that is certainly useful in overcoming the deficiencies of the Functional System of walking (in which the foot performs the function of double eye). These deficits are related to structural foot alterations due to falanga torture, but also generated from a bad information collection from the periphery (Mulder, 2007) (Bowering et al., 2013).
Recent studies, infact, show how the pain aetiology can be associated with an altered coherence between informations coming from periphery, that should be subsequently processed and modulated by the SNC in order to create a center-periphery unit useful to the organization (Perfetti, Pante', Rizzello, \& AAVV, 2015).

The alteration of information is related to the impairment of the body's ability to fragment and therefore to change itself following the interaction with the external environment, imposing on them to establish correct useful relations to the knowledge.

As for chronic pain caused by generalized tortures, physiotherapic treatment recommended by literature studies, also aim to intervene on the central sensitization mechanisms, through interventions that lead to reappropriation of a coherent body image.

In essence, the physiotherapic intervent suggested by some studies is aimed to teach patients strategies of articolar hygiene that avoid overloadings (eg. in the low back pain) (Olsen et al., 2007)back and feet, among previously tortured refugees settled in Denmark, and to compare associations between methods of torture and prevalent pain at baseline and at 10-year follow-up. Methods. 139 refugees previously exposed to torture in their home country were interviewed at a Danish rehabilitation clinic on average 8 years after their final release from confinement and re-interviewed 10 years later. Interviews focused on history of exposure to physical and mental torture and on pain in the head, back and feet prevalent at study. Results. The mean number of times imprisoned was 2.5 and the mean cumulative duration of imprisonment 19.4 months. The most frequent physical torture method reported was beating $(95.0 \%$.

Unfortunately, the rehabilitative intervention in no study is well clarified in terms of duration, frequency and type of exercise, so repeatability is definitely invalidated and the effectiveness of it continues to be uncertain.

\section{BIBLIOGRAPHY}

1. Amris, K., \& Rasmussen, O. V. (2009). Long-term consequences of falanga torture. (February), 33-40.

2. Amris, K., Rasmussen, O. V., \& Baykal, T. (2009). The diagnostic value of clinical examination after falanga. Journal on Rehabilitation of Torture Victims and Prevention of Torture, 5-11.

3. Amris, K., \& Williams, A. C. d. C. (2015). Managing chronic pain in survivors of torture. Pain Management, 5(1), 5-12. https://doi. org/10.2217/pmt.14.50

4. Başoğlu, M., Livanou, M., \& Crnobarić, C. (2007). Torture vs other cruel, inhuman, and degrading treatment: Is the distinction real or apparent? Archives of General Psychiatry, 64(3), 277-285. https://doi.org/10.1001/archpsyc.64.3.277

5. Beck, B. D., Lund, S. T., Søgaard, U., Simonsen, E., Tellier, T. C., Cordtz, T. O., ... Moe, T. (2018). Music therapy versus treatment as usual for refugees diagnosed with posttraumatic stress disorder (PTSD): Study protocol for a randomized controlled trial. Trials, 19(1), 1-20. https://doi.org/10.1186/s13063-018-2662-z

6. Blaauwendraat, C., Levy Berg, A., \& Gyllensten, A. L. (2017). One-year follow-up of basic body awareness therapy in patients with posttraumatic stress disorder. A small intervention study of effects on movement quality, PTSD symptoms, and movement experiences. Physiotherapy Theory and Practice, 33(7), 515-526. https://doi.org/10.1080/09593985.2017.1325957

7. Bowering, K. J., O’Connell, N. E., Tabor, A., Catley, M. J., Leake, H. B., Moseley, G. L., \& Stanton, T. R. (2013). The effects of graded motor imagery and its components on chronic pain: A systematic review and meta-analysis. Journal of Pain, 14(1), 3-13. https:/doi. org/10.1016/j.jpain.2012.09.007

8. Buhmann, C. B. (2014). Traumatized refugees: Morbidity, treatment and predictors of outcome. Danish Medical Journal, 61(8), 1-29.

9. Byard, R. W., \& Singh, B. (2012). Falanga torture: Characteristic features and diagnostic issues. Forensic Science, Medicine, and Pathology, 8(3), 320-322. https://doi.org/10.1007/s12024-011-9298-6

10. Camilli, A. (20017). I medici che curano le ferite invisibili della tortura. Internazionale.

11. Ciriello, M., \& Calabrese, M. (2019). L'intervento fisioterapico nel paziente con piede diabetico. Journal of Advanced Health Care, 1(2), 1-14. https://doi.org/10.36017/jahc1909-006

12. D'amato, S., Bonfigli, S., Cenci, C., \& Maraglino, F. P. (2017). Tubercolosi tra gli stranieri in Italia. Rapporto Osservasalute 2017, 2017(6), 301-339. Retrieved from http://missingmigrants.iom.int.

13. Danneskiold-Samsøe, S., Amris, S., \& Torp-Pedersen, S. (2007). Producing medicolegal evidence: Documentation of Torture versus the Saudi Arabian State of Denial. Torture, 17(3).

14. Danon, M., \& Miltenburg, A. (2001). Rifugiati politici e salute mentale. Intervento Tratto Dagli Atti Della Conferenza Internazionale Una Città Interculturale Da Inventare Esperienze Europee a Confronto. Padova.

15. de C Williams, A. C., \& Baird, E. (2016). Special Considerations for the Treatment of Pain from Torture and War. Current Anesthesiology Reports, 6(4), 319-326. https://doi.org/10.1007/s40140-016-0187-0

16. Edston, E. (2009). The epidemiology of falanga - incidence among Swedish. Torture, 19(1):27-3, 27-32. 
17. Frommberger, U., Angenendt, J., \& Berger, M. (2014). Post-Traumatic Stress Disorder-a Diagnostic and Therapeutic Challenge. Deutsches Arzteblatt International, 111(5), 59-65. https://doi.org/10.3238/arztebl.2014.0059

18. Geraci, S., \& Hamad, I. El. (2011). Migranti e accessibilità ai servizi sanitari: luci e ombre. Italian Journal of Public Health, 8(3), 14-20.

19. Grodin, M. A., Piwowarczyk, L., Fulker, D., Bazazi, A. R., \& Saper, R. B. (2008). Treating survivors of torture and refugee trauma: A preliminary case series using Qigong and T'ai Chi. Journal of Alternative and Complementary Medicine, 14(7), 801-806. https://doi. org $/ 10.1089 / \mathrm{acm} .2007 .0736$

20. Kaur, G. (2017). Chronic pain in refugee torture survivors. Journal of Global Health, 7(2), 1-3. https://doi.org/10.7189/jogh.07.020303

21. Kirstine Viller Hansen, A., Sloth Hansen-Nord, N., Smeir, I., Engelkes-Heby, L., \& Modvig, J. (2018). Impact of Narrative Exposure Therapy on torture survivors in the MENA region. Torture Journal, 27(3), 49-63. https://doi.org/10.7146/torture.v27i3.103977

22. Longacre, M., Silver-Highfield, E., Lama, P., \& Grodin, M. (2012). Complementary and alternative medicine in the treatment of refugees and survivors of torture: a review and proposal for action. Torture : Quarterly Journal on Rehabilitation of Torture Victims and Prevention of Torture, 22(1), 38-57.

23. Madsen, T. S., Carlsson, J., Nordbrandt, M., \& Jensen, J. A. (2016). Refugee experiences of individual basic body awareness therapy and the level of transference into daily life. An interview study. Journal of Bodywork and Movement Therapies, 20(2), 243-251. https://doi. org/10.1016/j.jbmt.2015.10.007

24. Martin-Saavedra, J. S., Vergara-Mendez, L. D., \& Talero-Gutiérrez, C. (2018). Music is an effective intervention for the management of pain: An umbrella review. Complementary Therapies in Clinical Practice, 32(March), 103-114. https://doi.org/10.1016/j. ctcp.2018.06.003

25. Masmas TN, Møller E, Buhmannr C, Bunch V, Jensen JH, Hansen TN, Jørgensen LM, Kjaer C, Mannstaedt M, Oxholm A, Skau J, Theilade L, Worm L, E. M. (2008). Asylum seekers in Denmark--a study of health status and grade of traumatization of newly arrived asylum seekers. Torture, 18(2):77-86.

26. Ministero della Salute. (2017). Linee guida per la programmazione degli interventi di assistenza e riabilitazione nonché per il trattamento dei disturbi psichici dei titolari dello status di rifugiato e dello status di protezione sussidiaria che hanno subito torture, stupri o altre form. 1-94. Retrieved from http://www.salute.gov.it/imgs/C 17 pubblicazioni_2599 allegato.pdf

27. Mulder, T. (2007). Motor imagery and action observation: Cognitive tools for rehabilitation. Journal of Neural Transmission, 114(10), 1265-1278. https://doi.org/10.1007/s00702-007-0763-z

28. Nyboe, L., Bentholm, A., \& Gyllensten, A. L. (2017). Bodily symptoms in patients with post traumatic stress disorder: A comparative study of traumatized refugees, Danish war veterans, and healthy controls. Journal of Bodywork and Movement Therapies, 21(3), 523-527. https://doi.org/10.1016/j.jbmt.2016.08.003

29. Olsen, D. R., Montgomery, E., Bøjholm, S., \& Foldspang, A. (2006). Prevalent musculoskeletal pain as a correlate of previous exposure to torture. Scandinavian Journal of Public Health, 34(5), 496-503. https://doi.org/10.1080/14034940600554677

30. Olsen, D. R., Montgomery, E., Bøjholm, S., \& Foldspang, A. (2007). Prevalence of pain in the head, back and feet in refugees previously exposed to torture: A ten-year follow-up study. Disability and Rehabilitation, 29(2), 163-171. https://doi.org/10.1080/09638280600747645

31. Olsen, D. R., Montgomery, E., Carlsson, J., \& Foldspang, A. (2006). Prevalent pain and pain level. (May).

32. Pacella, M. L., Hruska, B., \& Delahanty, D. L. (2013). The physical health consequences of PTSD and PTSD symptoms: A meta-analytic review. Journal of Anxiety Disorders, 27(1), 33-46. https://doi.org/10.1016/j.janxdis.2012.08.004

33. Palic, S., \& Elklit, A. (2009). An explorative outcome study of CBT-based multidisciplinary treatment in a diverse group of refugees from a Danish treatment centre for rehabilitation of traumatized refugees. Torture, 19(3):248-70.

34. Perfetti, C., Pante', F. A., Rizzello, C., \& AAVV. (2015). Il dolore come problema riabilitativo (Piccin, ed.).

35. Persson, A. L., \& Gard, G. (2013). Tortured refugees' expectations of a multidisciplinary pain rehabilitation programme: An explorative qualitative study. Journal of Rehabilitation Medicine, 45(3), 286-292. https://doi.org/10.2340/16501977-1101

36. Prip, K., \& Persson, A. L. (2008). Clinical findings in men with chronic pain after falanga torture. Clinical Journal of Pain, 24(2), 135-141. https://doi.org/10.1097/AJP.0b013e31815aac36

37. Prip, K., Persson, A. L., \& Sjölund, B. H. (2011). Self-reported activity in tortured refugees with long-term sequelae including pain and the impact of foot pain from falanga - A cross-sectional study. Disability and Rehabilitation, 33(7), 569-578. https://doi.org/10.3109/096 38288.2010.493597

38. Prip, K., Persson, A. L., \& Sjölund, B. H. (2012a). Pain when walking: Individual sensory profiles in the foot soles of torture victims - A controlled study using quantitative sensory testing. BMC International Health and Human Rights, 12(1). https://doi.org/10.1186/1472698X-12-40

39. Prip, K., Persson, A. L., \& Sjölund, B. H. (2012b). Sensory functions in the foot soles in victims of generalized torture, in victims also beaten under the feet (falanga) and in healthy controls - A blinded study using quantitative sensory testing. BMC International Health and Human Rights, 12(1). https://doi.org/10.1186/1472-698X-12-39

40. Rasmussen, O. V, Amris, S., \& Blaauw, M. (2002). Medical , physical examination. 46-53.

41. Rejali, D. (2009). Torture and democracy. Torture and Democracy, 1-849. https://doi.org/10.5771/9783845214986-81

42. Rica, C. (2016). Convention against Torture and Other Cruel, Inhuman or Degrading Treatment or Punishment (pp. 1-40). pp. 1-40.

43. Rights, P., \& Cruel, O. (2012). Convention Against Torture. SpringerReference, 27(December 1984). https://doi.org/10.1007/springerreference 308125

44. Roxendal, G. (1985). Body awareness therapy and the body awareness scale : treatment and evaluation in psychiatric physiotherapy. In Sweden. Retrieved from http://www.ibk.nu/abstracts/avhandling_roxendal.pdf

45. Savnik, A., Amris, K., Røgind, H., Prip, K., Danneskiold-Samsøe, B., Bojsen-Møller, F., ... Egund, N. (2000). MRI of the plantar structures of the foot after falanga torture. European Radiology, 10(10), 1655-1659. https://doi.org/10.1007/s003300000476

46. Sjölund, B. H., Kastrup, M., Montgomery, E., \& Persson, A. L. (2009). Rehabilitating torture survivors. Journal of Rehabilitation Medicine, 41(9), 689-696. https://doi.org/10.2340/16501977-0426

47. Stade, K., Skammeritz, S., Hjortkjær, C., \& Carlsson, J. (2015). "After all the traumas my body has been through, I feel good that it is still working."--Basic Body Awareness Therapy for traumatised refugees. Torture : Quarterly Journal on Rehabilitation of Torture Victims and Prevention of Torture, 25(1), 33-50. https://doi.org/10.7146/torture.v25i1.109507

48. Thomsen, A. B., Eriksen, J., \& Smidt-Nielsen, K. (2000). Chronic pain in torture survivors. Forensic Science International, 108(3), 155-163. https://doi.org/10.1016/S0379-0738(99)00209-1

49. Williams, A. C. d. C., \& Amris, K. (2017). Treatment of persistent pain from torture: review and commentary. Medicine, Conflict and Survival, 33(1), 60-81. https://doi.org/10.1080/13623699.2016.1242050

50. Williams, A. C. D. C., Peña, C. R., \& Rice, A. S. C. (2010). Persistent pain in survivors of torture: A cohort study. Journal of Pain and Symptom Management, 40(5), 715-722. https://doi.org/10.1016/j.jpainsymman.2010.02.018

51. Yang, Y., Li, X. Y., Gong, L., Zhu, Y. L., \& Hao, Y. L. (2014). Tai chi for improvement of motor function, balance and gait in Parkinson's disease: A systematic review and meta-analysis. PLOS ONE, 9(7), 1-9. https://doi.org/10.1371/journal.pone.0102942 